\title{
Preparation of Glucosamine Hydrochloride from Indigenous Shrimp Processing Waste
}

\author{
M. M. Islam **, S. M. Masum ${ }^{\text {b }}$, M. M. Rahman ${ }^{\text {a }}$ and A. A. Shaikh \\ ${ }^{a}$ Bangladesh Council of Scientific and Industrial Research (BCSIR), Dhanmondi, Dhaka-1205, \\ ${ }^{b}$ Department of Applied Chemistry \& Chemical Engineering, University of Dhaka, Dhaka-1000 and \\ ${ }^{c}$ Department of Chemistry, University of Dhaka, Dhaka-1000, Bangladesh.
}

\begin{abstract}
The present investigation described the effective preparation of glucosamine hydrochloride (GluHCl) from chitin which was extracted from indigenous shrimp shell. GluHCl has attracted much attention owing to its therapeutic activity in osteoarthritis and widely used dietary supplement. The key step involved was extraction of chitin from shrimp skeleton and then hydrolysis of chitin by concentrated hydrochloric acid. The reaction proceeds via break down of glycoside linkage. Structural analysis was carried out by melting point, TLC, FT-IR, elemental analysis and all the data were compared with that of standard GluHCl. The elemental $(\mathrm{C}, 32.75$; $\mathrm{H}, 6.51$; N, 6.20) analysis is good concord with the calculated value $(\mathrm{C}, 33.42 ; \mathrm{H}, 6.54 ; \mathrm{N}, 6.50)$. Absence of $v_{\max }$ at $1726 \mathrm{~cm}^{-1}$ indicates that GluHCl is a deacetylated product of chitin. The yields of the product mainly depend on reaction conditions. Maximum yield (63.5\%) was obtained when chitin was hydrolyzed with concentrated $\mathrm{HCl}$ for $1.30 \mathrm{~h}$.
\end{abstract}

Key words: Shrimp shell, Chitin, Acid hydrolysis, Glucosamine hydrochloride Osteoarthritis.

\section{Introduction}

Chitin is a natural polymer which is found in exoskeleton animals like shrimps. Chitin is the most second ubiquitous natural polysaccharide after cellulose on earth and is composed of $\beta$ - $(1 \rightarrow 4)$ linked 2-acetoamido-2-deoxy- $\beta$-D-glucose (Dutta et al., 2004) (Fig.1). GluHCl is an important derivative of chitin.

Glucosamine (2-Amino-2-deoxy-D-glucose) (Fig. 2) is an amino monosaccharide precursor of the disaccharide unit of glycosaminoglycan which is the building block of proteoglycans, being the ground substance of articular cartilage (Fattahi et al., 2008). Glucosamine exists as a component of proteoglycan in cartilage, skin, and connective tissue and recently has attracted much attention due to its therapeutic activity in osteoarthritis and been evaluated as a food supplement (Aiba et al., 2005). Glucosamine is mostly found cartilage and provides an important function in cartilage resilience and joint lubrication. Human body synthesizes glucosamine by combining glucose with amino acid glutamine (McGrow-Hill, 1966). Glucosamine has been widely promulgated to relieve symptoms in osteoarthritis (Anderson et al., 2005). Glucosamine products for arthritis are usually

\footnotetext{
* Corresponding author: E-mail: mmipavel@yahoo.com
}

formulated as the hydrochloride salt or glucosamine sulfate and are often combine with chondroitin sulfate (Abdel Fattah et al., 2001). In the USA it is one of the most commonly used non-vitamin, non-mineral, natural products used by adults as complementary or alternative medicine and most popular dietary supplement (Dahmer and Schiller, 2008). The preparation of glucosamine hydrochloride from chitin is a simple hydrolysis reaction. During this reaction, chitin is deacetylated and depolymerized to glucosamine hydrochloride in the presence of hydrochloric acid. Enzymatic hydrolysis of chitin to prepare $\mathrm{N}$-acetyl-D-glucosamine is reported in literature (Setgthbakset et al., 2008). Acid hydrolysis of chitin and chitosan is also reported (Novikov, 2004). This process involves two acid-catalyzed hydrolysis reactions, i,e. that of glycosidic linkage (depolymerisation) and that of the Nacetyl linkage (deacetylation). Edward (1955) illustrated the most accepted reaction mechanism for the acid catalyzed hydrolysis of a glycosidic linkage. Stryer (1995) illustrated the reaction mechanism for acid hydrolysis of the $\mathrm{N}$-acetyl linkage. It is also reported in literature that the exhaustive hydrolysis of chitin in the concentrated acid proceeds with the formation of acetic acid and D-glucosamine salt and the 


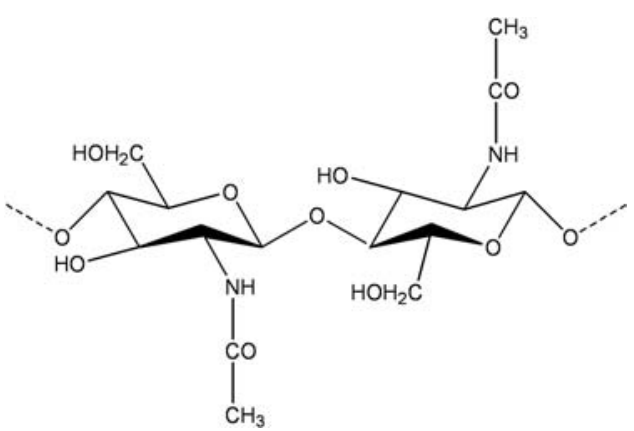

Fig. 1: Chemical structure of chitin.

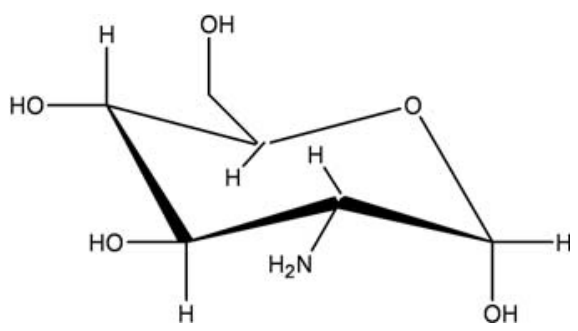

Fig. 2: Structure of glucosamine

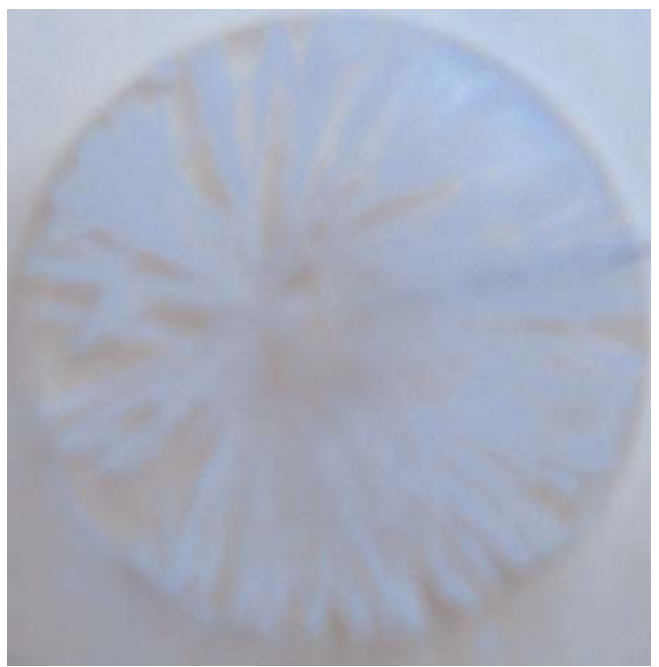

Fig. 3: Needle shape crystal of prepared GluHCl

hydrolysis of chitosan results in the formation of D-glucosamine salt (Shabrukova et al., 2002).

In weak acid chitin is hydrolyzed with the formation of $\mathrm{N}$ acetyl-D-glucosamine and D-glucosamine salt (Shabrukova et al., 2002).

$\left[\mathrm{C}_{6} \mathrm{H}_{9} \mathrm{O}_{5}\left(\mathrm{NH}-\mathrm{COCH}_{3}\right)\right]_{\mathrm{n}} \stackrel{\mathrm{HCl} \cdot \mathrm{H}_{2} \mathrm{O}}{\longrightarrow} x_{6} \mathrm{H}_{9} \mathrm{O}_{5}\left(\mathrm{NHCOCH}_{3}\right)$ $+\mathrm{N}$-acetyl-D-glucosamine $+\mathrm{y} \mathrm{C}_{6} \mathrm{H}_{11} \mathrm{O}_{5}\left(\mathrm{NH}_{2} \cdot \mathrm{HCl}\right)+$ $\mathrm{yCH}_{3} \mathrm{COOH}$
Hackman (1962) investigated the effect of $\mathrm{HCl}$ and other strong mineral acids on the size of the chitin chain and reported that most of the degradation of the chitin chain occurred during the first few minutes, that the products formed were oligosaccharides. The main goal of this present work was to prepare $\mathrm{GluHCl}$ from fishery waste materials which are hazard and toxic for environment. Shrimps are in general sold headless and often peeled of the outer shells and tail. About $30-40 \%$ by weight, shrimp raw material is discarded as waste when processed shrimp is headless, shell on products (Begum et al., 2006).

\section{Materials and Methods}

\section{Materials}

Shrimp shell materials were collected from Khulna, Bangladesh. D-(+) Glucosamine hydrochloride was purchased from KANTO CHEMICAL CO. INC. Japan as a standard. All the chemicals purchased from Merck were analytical grade.

\section{Preparation of Chitin}

Shrimp shells were scraped free of loose tissue, washed with cold water and dried in sun for 2 days. Chitin was extracted from shrimp shell following standard procedure ( Hossain et al., 2005; Rodde et al., 2008). The process mainly involved the following steps: Demineralizations of Shells. In this step, the shells were suspended in $4 \% \mathrm{HCl}$ at room temperature in the ratio of $1: 14(\mathrm{w} / \mathrm{v})$. After 36 hours, the shells were quite squashy and were rinsed with water to remove acid and calcium chloride. Deproteinization of Shells. The demineralized shells were then treated with $5 \% \mathrm{NaOH}$ at $90^{\circ} \mathrm{C}$ for 24 hours with a solvent to sold ratio of $12: 1(\mathrm{v} / \mathrm{w})$. The residue was then collected and washed to neutrality in running tap water. Then it was dried in sun. Yield of chitin was $18.23 \%$.

\section{Preparation of Glucosamine hydrochloride}

Chitin was treated with different ratios and concentrations of hydrochloric acid (Table I). The following major steps were under taken to obtain GluHCl from chitin.(i) grinding the chitin to fine particle; (ii) hydrolysis the chitin with $\mathrm{HCl}$ at $90^{\circ} \mathrm{C}$ or room temperature; (iii) dissolving the black precipitate in water and decolorizing with activated charcoal; (iv) filtering the solution and discarding the solids; (v) evaporating the solution to recover $\mathrm{GluHCl}$ crystal at $45^{\circ} \mathrm{C}$; (vi) 
washing the crystals with ethanol; (vii) drying the crystals at $50^{\circ} \mathrm{C}$ in an oven. well agreement with the reported data (Pavia et al., 2001; Silverstien et al., 1991). A broad strong stretching band in

Table I: Optimizing the reaction conditions

\begin{tabular}{c|c|c|c|c|c|c}
\hline Entry & $\begin{array}{c}\text { Amount of } \\
\text { Chitin }(\mathrm{g})\end{array}$ & $\begin{array}{c}\text { Amount of } \\
\mathrm{HCl}(\mathrm{mL})\end{array}$ & $\begin{array}{c}\text { Conc. of } \\
\mathrm{HCl}(\%)\end{array}$ & $\begin{array}{c}\text { Reaction } \\
\text { time }(\mathrm{h})\end{array}$ & $\begin{array}{c}\text { Reaction } \\
\text { temp. }\left({ }^{\circ} \mathrm{C}\right)\end{array}$ & $\begin{array}{c}\text { Yield } \\
(\%)\end{array}$ \\
\hline 1 & 3 & 60 & 37 & 1 & 90 & 52.12 \\
2 & 3 & 60 & 37 & 1.30 & 90 & 63.45 \\
3 & 3 & 60 & 37 & 2 & 90 & 55.36 \\
4 & 3 & 60 & 37 & 24 & Room temp & 51.23 \\
5 & 3 & 60 & 37 & 48 & Room temp & 60.32 \\
\hline
\end{tabular}

\section{Results and Discussion}

The purity and quality of the obtained GluHCl is demonstrated by its melting point, IR spectra, TLC method which are similar with the results of that standard GluHCl. The melting point of the prepared GluHCl was $192-194{ }^{\circ} \mathrm{C}$ which is good agreement with 191-192 ${ }^{\circ} \mathrm{C}$ for standard GluHCl. The spectral data FT-IR spectrometry of chitin and prepared GluHCl are given bellow;

Chitin FT-IR (KBr): 3849.7, 3421.5, 2935.5, 2360.7, 2343.4, $1726.5,1627.8,1558.4,1542.9,1488.9,1475.4,1404.1$, 1384.8, 1330.8, 1261.4, 1195.8, 1112.4, 896.8, 619.1, 603.7, $513.0,453.2,408.9 \mathrm{~cm}^{-1}$.

Prepared GluHCl FT-IR (KBr):3600, 2788.9, 2613,9 2472.6, $1946.0,1888.2$, 1831.3, 1801.4, 1616.2, 1585.4, 1533.2, $1456.2,1421.4,1394.4,1363.6,1332.7,1317.3,1217.3$, $1249.8,1184.2,1137.9,1002.9,912.3,887.2,854.4,773.4$, $698.2,592.1,543.9,507.2,434.0,408.9 \mathrm{~cm}^{-1}$.

Standard GluHCl FT-IR (KBr):3600, 2842.9, 2570.9, 2538.1, 2432.1, 1944.1, 1830.3, 1801.4, 1616.2, 1583.4, $1535.2,1421.4,1394.4,1363.6,1332.7,1317.3,1217.0$, $1249.8,1184.2$, 1002.9, 973.3, 887.2, 854.4, 773.4, 698.2, $592.1,545.9,507.2,434.0,407.0 \mathrm{~cm}^{-1}$.

The finger print of the FT-IR spectra of prepared and standard GluHCl does not show any excess peaks. The FT-IR spectra of prepared GluHCl showed a deacetylation because the wave no. at about $1726 \mathrm{~cm}^{-1}$ for $\mathrm{C}=\mathrm{O}$, which exist in IR spectrum of chitin, has disappeared. The absorption bands at 1616.2 and $1585-1535 \mathrm{~cm}^{-1}$ are due to the $\mathrm{NH}_{3}{ }^{+}$in GluHCl for asymmetrical and symmetrical $\mathrm{NH}_{3}{ }^{+}$bending which is the region $3400-2500 \mathrm{~cm}^{-1}$ also proved the formation of $\mathrm{NH}_{3}{ }^{+}$in $\mathrm{GluHCl}$ as in reported data (Pavia et al., 2001; Silverstien et al., 1991). TLC plate was prepared manually, eluting solvents were butanol-acetic acid-water (3:1:1) and ninhydrin was used as a locating agent. The $\mathrm{R}_{\mathrm{f}}$ value of spots was 0.46 for the both of prepared and standard GluHCl. TLC did not show any other spots for impurities. The needle shape crystals of prepared GluHCl (Fig. 3) also prove its high purity. The yield is high when the chitin was hydrolyzed with $37 \% \mathrm{HCl}$ at $90^{\circ} \mathrm{C}$ for $1.30 \mathrm{~h}$. The yield decreased when the chitin was hydrolyzed for $2 \mathrm{~h}$. The explanation is that some of the $\mathrm{GluHCl}$ may decompose to fragments. Anal. Calcd for $\mathrm{C}_{6} \mathrm{H}_{11} \mathrm{O} 5\left(\mathrm{NH}_{2} . \mathrm{HCl}\right)$ : C, 33.41; H, 6.54; N, 6.50 Found: C, 32.75; H, 6.51; N, 6.20. The existence of nitrogen and chlorine was also confirmed by Lassaigne test.

\section{Conclusion}

Based on the experimental results, it is concluded that the preparation of GluHCl by acid hydrolysis method is effective. The method is convenient and simple in procedure. The preparation of $\mathrm{GluHCl}$ from shrimp shell via chitin would successfully minimize the environmental pollution by the shrimp shell processing.

\section{Acknowledgement}

The authors wish to thank Professor S.M. Imamul Huq, Chairman BCSIR, Jasim Uddin Chowdhury, Director Dhaka Laboratories BCSIR and S.K. Roy CSO, Division in-Charge Chemical Research Division for rendering their magnanimous help and financial support during the study. Authors are cordially grateful to former chief scientific officer Md. 
Asaduzzaman and Bazlul Karim Akanda for their valuable suggestions and cordial help.

\section{References}

Abdel Fattah W and Hammad, T. (2001). Chondroitin sulfate and glucosamine: A review of their safety profile. J.A.N.A. 3: 16-23.

Aiba S. (2005). Production of N-acetyl-D-glucosamine from Chitin Using Crude Enzyme, Preparation in Large Scale. Journal of Metals, Materials and Minerals. 15(1): 23-25.

Anderson J. W., Nicolasi R. J. and Borzelleea J. F. (2005). Glucosamine effect in humans: a review of effects on glucose metabolism, side effects, safety considerations and efficacy. Food and Chem. Toxicol. 43: 187-201.

Begum S., Ikejima K., Ara H. and Islam M. Z. (2006). Solar Drying as an Option for Shrimp Processing Biowaste in Khulna District- Southwest Bangladesh. J. Appl. Sci. 6(5): 1220-1224.

Dahmer S. and Schiller R. M. (2008). Glucosamine. Am. Fam. Physician, 78(4): 471-476.

Dutta P. K., Dutta J. and Tripathi V. S. (2004). Chitin and Chitosan : Chemistry, properties and application. $J$. Sci. and Ind. Res. 63: 20-31.

Edward J. T. (1955). Stability of glycosides to acid hydrolysis-A conformational analysis. Chemistry and industry. 36: 1102-1104.

Fattahi A., Ghorat M., Pourjavadi A., Kurdtabar M. and Torabi A. A. (2008). DFT/B3LYP Study of Thermochemistry of D-glucosamine, a Representive Polyfunctional Bio-organic Compound. Scientia Iranica, 15(4): 422-429.

Hackman R. H. (1962). Studies on Chitin 5. Action of Mineral Acids on Chitin. Australian J. Biol. Sci. 15(3): 526-532.
Hossain Z., Asaduzzaman, Kashem M. A., Akanda B. K., Roy S. K. and Islam S. (2005). Studies on the Chitin content of Some Waste Materials of Bangladesh. Bangladesh J. Sc. Ind. Res. 40(3-4): 163-168.

McGrow-Hill. (1966). Enc. Of Science \& Technol. 3: 538539.

Novikov V. Yu. (2004). Acid hydrolysis of Chitin and Chitosan. Russian J. Appl. Chem. 77( 3): 484-487.

Pavia D. L., Lampman G. M. and Kriz G. S. (2001). Introduction to Spectroscopy. Thomson learning inc., Third Edition, $72-74$ \& 78.

Rodde R. H., Enbu A. and Varum K. M. (2008). A seasonal study of the chemical composition and chitin quality of shrimp shells obtained from northern shrimp. Carbohyd. Polym. 71: 388-393.

Setthakaset P., Pichyangkura R., Ajavakom A. and Sukwattanasit M. (2008). Preparation of N-acetyl-DGlucosamine Using Enzyme from Aspergillus sp. Journal of Metals, Materials and Minerals. 18(2): 5357.

Shabrukova N. V., Shestakova L. M., Zainetdinova D. R., and Gamayurova V. S. (2002). Research of acid hydrolysis of chitin -glucan and chitosan- glucan complexs. Chemistry and Computational Simulation. Butlervo Communications, 2(4).

Silverstien R. M., Clayton Bassler G., Terence C. Morill (1991). Spectrometric Identification of Organic Compounds. John wiley \& sons inc., Fifth Edition, 125.

Stryer L. (1995). Biochemistry 4th ed. W. H. Freeman and Company, New York.

Received : August 18, 2010;

Accepted : December 05, 2010 